\title{
Editorial
}

\section{Sugar-sweetened beverage taxation: an update on the year that was 2017}

It has now been four years since the implementation of the Mexican sugar-sweetened beverage (SSB) tax at the beginning of 2014 - the first substantial, nationwide tax on SSB for health-related reasons. The enactment of this SSB tax, its robust evaluation and positive effects on reducing SSB purchases set a path for increasing global action in the years to follow. The implementation of SSB taxes as part of wider efforts to address obesity and diet-related chronic diseases was recognized to be at a tipping point in $2016^{(1)}$. Unlike other recommended obesity prevention policies, such as restrictions on unhealthy food marketing to children, SSB taxes are fast becoming a norm in the USA and elsewhere around the globe, and the scientific evidence base is increasing and strengthening. Contradicting the view that SSB taxes are a progressive or left-wing preference, a recent study found that most SSB taxes are implemented by conservative or right-wing governments ${ }^{(2)}$. A recent review ${ }^{(3)}$ on key policy lessons from health taxes does, however, highlight the importance of being clear about the primary goal of the tax as health taxes remain vulnerable to hostile lobbying. Earmarking health taxes for health spending was clearly found to increase both public and political support for their implementation.

Here we provide an updated timeline of action (below and Fig. 1) and highlight evidence and lessons for the year that was 2017 .

\section{Notable action}

Much of the SSB tax action in 2017 was concentrated in the USA, with the implementation of SSB taxes in six cities following city council or public vote (all approved in 2016 with the exception of Seattle, Washington, which was approved in June 2017). In the Middle East the highest SSB taxes to date were implemented in Saudi Arabia and United Arab Emirates. Other countries and jurisdictions that joined the SSB tax crusade included Portugal, Brunei and the Catalonian region of Spain. This year also saw Estonia and Thailand pass legislation on SSB taxes, with taxation due to be mandated in the coming years. Meanwhile, the UK and Ireland are preparing for a 2018 implementation of a two-tiered levy on the sugar content in SSB. Below we summarize each of these actions. For specific design elements of each tax (magnitude, type of tax and targeted products), see Fig. 1.

\section{Actions in the USA}

After defeating a relentless \$US 9 million campaign by the American Beverage Association opposing the SSB tax proposal in $2016^{(4)}$, Philadelphia adopted the SSB tax legislation in January 2017. The tax was introduced with the explicit goal of financing universal pre-kindergarten, for which broad support existed, and deliberately not framed as a health intervention, to avoid contentious debates about the role of government in changing individual behaviour ${ }^{(5)}$. The Mayor of Philadelphia announced that as of June 2017, the tax had funded 2000 pre-school childhood education placements and provided 4500 neighbourhood public-school students and their families with community school supports at nine different schools $^{(6)}$.

April saw the implementation of an SSB tax in Albany, California ${ }^{(7)}$. Drinks distributed to small retailers (<\$S 100000 in annual gross receipts) are excluded. Revenue will go into a general city fund, with an informal advisory committee to make recommendations as to how money should be spent. Cook County, Illinois followed in July when the Cook County Sweetened Beverage Tax Ordinance ${ }^{(8)}$ came into effect, with the primary purpose to raise revenue to alleviate budget deficit. The tax was repealed three months later following a veto vote by the Cook County Board of Commissioners in response to persistent public pressure fuelled by the soda industry, which reportedly channelled millions into media, lobbying and political activity to oppose the tax ${ }^{(9)}$.

In July, Boulder, Colorado effected its SSB tax ${ }^{(10)}$. Revenue has been earmarked primarily for supporting health, wellness and chronic disease programmes for those identified as most at risk. Revenue will also be used to cover the administrative costs of the $\operatorname{tax}^{(10)}$. Also in July, the city of Oakland, California implemented an SSB tax ${ }^{(11)}$. Small business distributors ( $<$ WS 100000 in annual gross revenue) are excluded from the tax. Revenue has been allocated to general funds with a nine-member Community Advisory Board providing recommendations to the city council as to how money could be spent on programmes that prevent or reduce the health consequences associated with regular SSB consumption. The city of Seattle, Washington passed a council vote $7-1$ in favour of a Sweetened Beverage Tax in June, to take effect in January $2018^{(12)}$. The tax is reduced (from 1.75 cents to 1 cent per fluid ounce) for manufacturers with an international gross income of more than \$US 2 billion but less than 


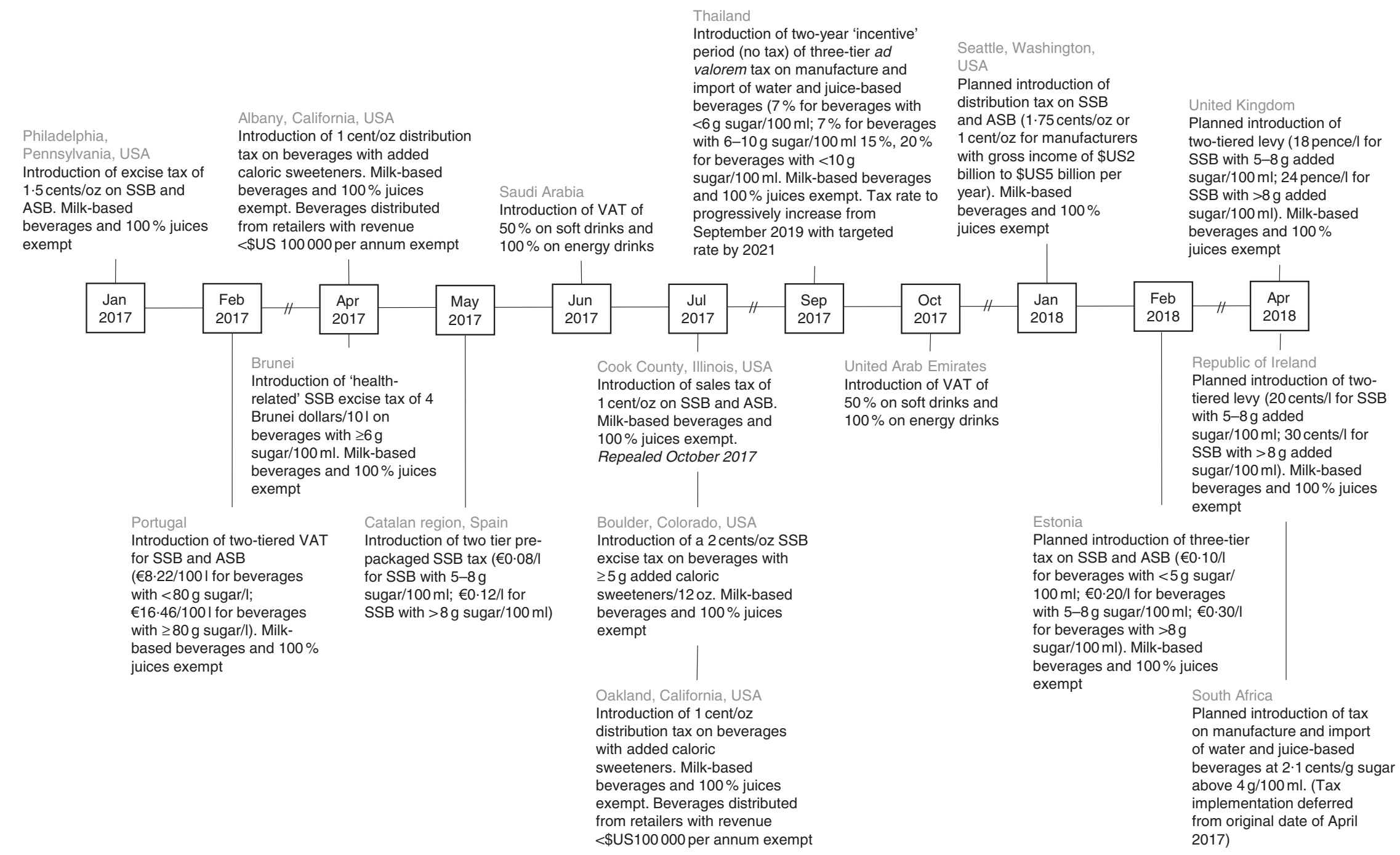

Fig. 1 Timeline of notable international progress of sugar-sweetened beverage (SSB) taxation, 2017-18 (VAT, Value Added Tax; ASB, artificially sweetened beverage) 
\$US 5 billion. It has been suggested that $20 \%$ of the revenue raised from the tax will be directed to one-off city expenditures for 5 years, with the remaining revenue to be allocated to a range of public health services, including support for public health and healthy food initiatives, programmes to address inequalities in health, and general administration costs relating to the tax.

While the US city taxes outlined above were successfully adopted by public or council vote (albeit later repealed in Cook County), a citizen vote for an SSB tax in Santa Fe, New Mexico (with revenue proposed to be earmarked for early childhood programmes) failed, with $42 \%$ in support of the tax. While it is unclear why the SSB tax bill in Santa Fe failed, it has been speculated that the lack of early and thoughtful engagement with the public, both in terms of the health risks associated with regular SSB consumption and how the revenue from that tax may be reinvested, may have influenced the outcome $^{(13)}$.

\section{Actions in otber countries}

At the national level, in February, Portugal implemented a two-tier Value Added Tax to beverages with added sugar and other sweeteners ${ }^{(14)}$. There is an indication that the tax design will be modified in the next budget, but exactly why this is the case or what modifications will occur is currently unclear.

In April, in an attempt to align the nation 'towards a healthier society', Brunei introduced a health-related SSB tax as part of a broader tax strategy for the nation ${ }^{(15)}$. This SSB tax came into effect in April 2017. There has been no indication as to how revenue will be used.

Approximately a month later, in May, the Catalan regional government in Spain implemented a two-tier tax on prepackaged SSB, enacted throughout the whole of Catalonia, regardless of manufacturer origin ${ }^{(16)}$. Importantly, the bill stipulates that the taxpayer (i.e. the manufacturer) is required to pass the tax on to the end consumer. However, it is unclear what mechanisms are in place to enforce this. In June the Spanish trade associations and companies united in a request to the Spanish Government to reverse the tax through an appeal to the constitutional court (which, to date, has not resulted to any legislative changes).

June saw Saudi Arabia implement the largest national SSB tax to date (after approval in January 2017) as part of a much broader Value Added Tax Framework Agreement to raise general government revenue as income from natural resources declines ${ }^{(17)}$. Unusual for a country of very few consumption taxes and no income tax, this policy represented the largest tax to date (50\% tax on soft drinks and $100 \%$ tax on energy drinks). The United Arab Emirates followed suit in October $2017^{(18)}$.

This year Thailand became the first South-East Asian country to announce a three-tiered excise tax on SSB. The policy came into action in September, beginning with a two-year 'incentive' period, where tax rates have not, and will not, change, but manufacturers are encouraged to reformulate to lower-sugar products. As of September 2019, it is expected that the tax rate will increase progressively to achieve the targeted tax rate by 2021 .

Meanwhile the UK and Ireland prepare for an April 2018 SSB tax implementation. Ireland released details of its SSB tax this year, of which the design (in terms of both magnitude and date of implementation) closely aligns with that of the UK to retain price parity and reduce cross-border trade between the Republic of Ireland and Northern Ireland. The intention of targeting sugar in these SSB taxes, rather than the beverage itself, is to promote product reformulation to lower-sugar beverages. Indeed, in March this year, the UK Office for Budget Responsibility released revised SSB tax revenue predictions, substantially reducing the expected revenue (a reduction of more than $£ 150$ million (\$US 196 million) in 2021-22), reporting that beverage manufacturers have responded to the imminent policy with more aggressive reformulation than initially expected ${ }^{(19)}$. The report also announced that the original exclusion of small producers and importers from the SSB tax would be retracted for importers of major brands, regardless of the volume imported (which is expected to increase revenue by approximately by $£ 45$ million (\$US 59 million) in 2021-22).

\section{Real-world evidence}

Key evidence from real-world SSB taxes released this year were those relating to the one-year results from Berkeley, California and the two-year results from Mexico. While these studies are both somewhat limited in causal inference due to their observational nature, the similar evaluation conclusions from two quite different contexts largely strengthen the body of evidence of real-world effectiveness. Preliminary evaluation of beverage price changes following the implementation of an SSB tax in Barbados was also released this year.

\section{Evidence from Mexico}

The two-year evaluation of a peso per litre SSB tax in Mexico was published in March $2017^{(20)}$. Store purchase data for 6645 households from January 2012 to December 2015 revealed a sustained reduction in the purchase of taxed beverages two years post policy implementation. While the reduction in SSB purchases increased over time in the first 12 months post policy implementation, this reduction stabilized in the second 12 months at an average of $9.7 \%$ reduction compared with predicted purchases in 2015 (average $5.5 \%$ reduction in 2014). Similar to the 12-month results, the decline in SSB purchases was greatest for the lowest-income households (average 9.0\% reduction in 2014 and $14.3 \%$ in 2015 compared with 
high-income households, where there was a $4.4 \%$ reduction in 2014 and a $5.6 \%$ reduction in 2015) and was driven predominantly by a reduction in non-carbonated beverage purchases. The increased purchase of untaxed beverages was also sustained over the two-year post-tax period ( $2 \cdot 1 \%$ increase). Another study by the same lead author this year examined variation in the 12-month post-SSB tax results in Mexico according to urban or rural location and household composition. This analysis revealed that tax pass-through and the reduction in SSB purchases were lesser in rural areas of Mexico compared with urban $\operatorname{areas}^{(21)}$. Moreover, in September, contrary to industry rhetoric, the publication of an analysis three years post SSB tax policy implementation in Mexico demonstrated no change in employment in the non-alcoholic beverage and non-essential energy-dense food manufacturing industries $^{(22)}$.

2017 also saw the release of industry-funded research evaluating the impact of the Mexican SSB tax on SSB sales $^{(23)}$. This research from the Autonomous University of Nuevo Leon (UANL), which used monthly industry timeseries data of soft drink purchases between January 2007 and March 2017, concluded that the tax was associated with a reduced per capita consumption of soft drinks of $3.8 \%$. Variations across higher- and lower-income households were not reported. Contrary to the beverages industry's propositions, these results are not in contrast with those of Colchero et al. ${ }^{(20)}$, who also estimated a small impact of the tax on carbonated beverages; as per the evidence described above, reductions in SSB purchases were driven primarily by a reduction in non-carbonated SSB.

Euromonitor International also released an analysis of aggregate SSB sales data for Mexico this year ${ }^{(24)}$, reporting a near full recovery in national soft drink sales in 2016 (0.2\% growth in soft drink sales in 2016) since the implementation of the SSB tax in 2014. This is in direct contrast to the findings reported by Colchero et al. ${ }^{(20)}$ and may be explained by two key differences. First, similar to the Mexican SSB tax evaluation by the UANL, this report focuses narrowly on 'soft drinks' only, and does not account for non-carbonated SSB. Second, Euromonitor data represent national aggregate sales and therefore do not take account of population growth in Mexico, which has been increasing by $1.2 \%$ per year. In other words, even if the per capita consumption of soft drinks remained unchanged over the time period, total national soft drinks sales would increase ${ }^{(25)}$

Interestingly, 2017 also revealed a leak of an internal email exchange between Coca-Cola executives ${ }^{(26)}$, highlighting findings from industry-funded research. In an email, Kerry Tressler, Director for Public Affairs for CocaCola, states: 'Multiple studies from well-respected institutions in Mexico (ITAM [Mexico Autonomous Institute of Technology], ColMex [The College of Mexico], and UANL, supported by funding from industry) make clear the tax was ineffective'. These leaked emails revealed that the evidence suggesting a return of SSB sales to pre-tax trends, two years post policy implementation, was also funded by industry. Similar comments were made relating to a study demonstrating an increase in business closures following SSB tax implementation, which was done by 'a key member of the coalition'.

\section{Evidence from Berkeley, California}

The 12-month analysis of the Berkeley, California, pennyper-ounce SSB excise tax was published in April 2017. An analysis of twenty-six different stores revealed complete tax pass-through from retailers to consumers in large and small chain supermarkets and gas stations, partial-pass through in pharmacies and negative pass-through in independent corner stores and independent gas stations ${ }^{(27)}$. An analysis of beverage prices from point-of-sale scanner data on 15.5 million supermarket checkouts (from two large chains) found an average tax pass-through of $67 \%$ across all SSB (0.67 cents per ounce), with complete pass-through for carbonated beverages and energy drinks. Using this same source of data, sales of SSB (in ounces) were estimated to decline by $9.6 \%$ compared with projected trends of SSB sales if the tax were not implemented. Conversely, sales of SSB in non-Berkeley stores located in comparison cities rose by $6.9 \%$. Sales of untaxed beverages rose by $3.5 \%$ in Berkeley compared projected trends compared with $0.5 \%$ for non-Berkeley stores. Importantly, consumer spending per transaction did not change significantly and store revenue tracked as expected if the policy were not in place, representing minimal financial impact to consumers and retailers. In addition to the analysis of objective sales data, that study also collected self-reported beverage intake data from a relatively modest number (and response rate) of adult Berkeley residents ( $n$ 957; response rate 17.4\%). In the analysis, reductions in mean daily SSB intake in grams $(-19 \cdot 8 \%)$ and in mean per capita SSB energy intake $(-13 \cdot 3 \%)$ were not statistically significant.

\section{Evidence from Barbados}

Finally, a descriptive analysis of the initial beverage price changes following implementation of a $10 \%$ ad valorem SSB tax in September 2015 in Barbados, revealed an average $5.9 \%$ increase in SSB prices and a relatively stable non-SSB price in the two quarters after the tax was implemented $^{(28)}$. An ongoing evaluation of the Barbados tax is planned to assess longer-term changes in both beverage prices and sales.

\section{Looking forward}

Next year is shaping up to be another big year for SSB tax implementation. San Francisco's 1 cent-per-ounce SSB tax is set to take effect in January. Estonia is due to follow in January, and the UK and Ireland in April. After a deferred implementation date of April 2017 for the South 
African SSB tax (following stakeholder submissions to the proposed bill which government is now reviewing), it is also expected that this tax will be implemented next year in April. Whether this comes with amendments to the bill is unclear. In the Philippines the president has called for tax on SSB using locally produced sugar with revenue to be earmarked for feeding programmes that address undernutrition; however, this is yet to pass through government.

In general, confidence of policy makers in implementing SSB taxes seems to be increasing as some countries start implementing much higher levies and other countries begin to contemplate taxing junk food more broadly, such as Chile ${ }^{(29)}$. Evidence for these broader based taxes is also mounting, with the release of the two-year evaluation of the $8 \%$ tax on non-essential energy-dense foods in Mexico this year ${ }^{(30)}$. Using longitudinal data on Mexican household purchases between 2012 and 2015, that study demonstrated a $7.4 \%$ decline in the purchase of taxed items, two years post policy implementation (up from $4.8 \%$ one year post policy implementation). Importantly, this effect was greatest among households considered to have a greater preference for taxed food products $(12.3 \%$ decline in non-essential energydense foods two years post policy implementation).

Industry will continue to act as a formidable opponent to action, so it will be crucial that all polices are embedded in comprehensive and robust evaluation frameworks and the results disseminated widely ${ }^{(31)}$. The message that an SSB tax cannot be viewed as a magic bullet to solve the problem of obesity must be actively reiterated and the evidence on the impact of other health outcomes, in particular dental health, strengthened. Long-term impacts of such taxes on population rates of obesity are likely to be small, but should not take away the importance of such policies in the pursuit of healthier population diets reducing diet-related ill health. 2017 proved to be a significant year for international SSB tax action. We expect 2018 to be equally momentous.

\section{Acknowledgements}

Financial support: This editorial received no specific grant from any funding agency in the public, commercial or not-for-profit sectors. Conflict of interest: The authors declare no conflicts of interest. Authorship: All authors contributed equally to this editorial. Ethics of human subject participation: Not applicable.

Kathryn Backholer and Miranda Blake

The Global Obesity Centre (GLOBE) School of Health and Social Development Deakin University

Locked Bag 20000, Geelong, VIC 3220, Australia Email: Kathryn.backholer@deakin.edu.au
Department of Epidemiology and Preventive Medicine, School of Public Health

Monash University Melbourne, Australia

Stefanie Vandevijvere

Department of Epidemiology and Biostatistics School of Population Health

University of Auckland

Auckland, New Zealand

\section{References}

1. Backholer K, Blake M \& Vandevijvere S (2016) Have we reached a tipping point for sugar-sweetened beverage taxes? Public Health Nutr 19, 3057-3061.

2. Hagenaars LL, Jeurissen PPT \& Klazinga NS (2017) The taxation of unhealthy energy-dense foods (EDFs) and sugar-sweetened beverages (SSBs): an overview of patterns observed in the policy content and policy context of 13 case studies. Health Policy 121, 887-894.

3. Wright A, Smith KE \& Hellowell M (2017) Policy lessons from health taxes: a systematic review of empirical studies. BMC Public Health 17, 583.

4. Centre for Science in the Public Interest (2016) Big Soda vs. Public Health (2016 Edition). https://cspinet.org/resource/ big-soda-vs-public-health-1 (accessed October 2017).

5. Purtle J, Langellier B \& Le-Scherban F (2017) A case study of the Philadelphia sugar-sweetened beverage tax policymaking process: implications for policy development and advocacy. J Public Health Manag Pract, (Epublication ahead of print version).

6. City Council of Philadelphia (2017) Mayor Kenney and Council President Clarke's written testimony in support of the Philadelphia beverage tax. http://phlcouncil.com/mayorkenney-council-president-clarkes-written-testimony-supportphiladelphia-beverage-tax (accessed September 2017).

7. City of Albany California (2016) Ordinance 2016-02. An ordinance of the city of Albany enacting a general tax on the distribution of sugar-sweetened beverage products. http:// www.albanyca.org/home/showdocument?id=28928 (accessed September 2017).

8. Cook County Government (2017) Cook County Sweetened Beverage Tax. https://www.cookcountyil.gov/service/ sweetened-beverage-tax (accessed September 2017).

9. Dewey C (2017) Why Chicago's soda tax fizzled after two months - and what it means for the anti-soda movement. The Washington Post, 10 October. https://www.washingtonpost.com/news/wonk/wp/2017/10/10/why-chicagos-sodatax-fizzled-after-two-months-and-what-it-means-for-the-antisoda-movement/?utm_term $=.96$ f09bbdd335 (accessed October 2017).

10. City of Boulder Colorado (2017) Five things to know about the Sugar-Sweetened Beverage Tax. https://bouldercolorado. gov/newsroom/sugar-sweetened-beverage-tax (accessed September 2017).

11. City of Oakland California (2016) Resolution 86161. http:// www2.oaklandnet.com/w/OAK063795 (accessed September 2017).

12. Seattle City Council (2017) Draft Rule - 5-953 Sweetened Beverage Tax. http://www.seattle.gov/documents/ departments/fas/rules/draft-rules-sweetened-beverage-tax.pdf (accessed September 2017).

13. Centre for Science in the Public Interest (2017) Santa Fe soda tax loss provides important lessons. Statement of CSPI President Michael F. Jacobson. https://cspinet.org/news/ 
santa-fe-soda-tax-loss-provides-important-lessons-20170503 (accessed September 2017).

14. AT Autoridade (2017) Codigo Dos Impostos Especiais De Consumo (CIEC). CIEC (Decreto-Lei n. ${ }^{\circ} 73 / 2010$, de 21/06). http://www.dgaiec.min-financas.pt/NR/rdonlyres/314EF2B67EFE-4BF5-A8F2-4D8B61082810/0/CIEC.pdf （accessed October 2017).

15. Brunei Ministry of Finance (2017) Amendments to the customs import and excise duties effective 1st April 2017. https://www.brudirect.com/news.php?id=24304 (accessed October 2017).

16. Generalitat de Catalunya (2017) Tax on sugary drinks. http://web.gencat.cat/en/actualitat/detall/Impost-sobrebegudes-ensucrades (accessed September 2017).

17. Vision 2030, Kingdom of Saudi Arabia (2017) Fiscal Balance Program: Balanced Budget 2020. http://vision2030.gov.sa/ sites/default/files/attachments/BB2020_EN.pdf (accessed October 2017).

18. Burki TK (2017) Tax on tobacco and sugary drinks in the United Arab Emirates. Lancet Oncol 18, e566.

19. Office for Budget Responsibility (2017) Economic and fiscal outlook - March 2017. http://budgetresponsibility.org.uk/efo/ economic-fiscal-outlook-march-2017/ (accessed October 2017).

20. Colchero MA, Rivera-Dommarco J, Popkin BM et al. (2017) In Mexico, evidence of sustained consumer response two years after implementing a sugar-sweetened beverage tax. Health Aff (Millwood) 36, 564-571.

21. Colchero MA, Molina M \& Guerrero-Lopez CM (2017) After Mexico implemented a tax, purchases of sugar-sweetened beverages decreased and water increased: difference by place of residence, household composition, and income level. J Nutr 147, 1552-1557.

22. Guerrero-López CM, Molina M \& Colchero MA (2017) Employment changes associated with the introduction of taxes on sugar-sweetened beverages and nonessential energy-dense food in Mexico. Prev Med, (Epublication ahead of print version).
23. Arteaga JC, Flores D \& Luna E (2017) The effect of a soft-drink tax in Mexico: a time series approach. Facultad de Economía, Universidad Autónoma de Nuevo León, Nuevo León, México. https://mpra.ub.uni-muenchen.de/80831/1/ MPRA_paper_80831.pdf (accessed October 2017).

24. Euromonitor International (2017) Soft Drinks in Mexico. http://www.euromonitor.com/soft-drinks-in-mexico/report (accessed October 2017).

25. Cherukupalli R (2016) Growth rates and aggregates: bringing data to the soda wars. http://globalhealth.thelancet.com/ 2016/06/10/growth-rates-and-aggregates-bringing-data-sodawars (accessed October 2017).

26. Pfister K (2016) Coke funds research against soda taxes. https://medium.com/cokeleak/coke-funded-research-againstsoda-taxes-4289d897bde3 (accessed October 2017).

27. GBD 2015 Obesity Collaborators, Afshin A, Forouzanfar MH et al. (2017) Health effects of overweight and obesity in 195 countries over 25 years. $N$ Engl J Med 377, 13-27.

28. Alvarado M, Kostova D, Suhrcke M et al. (2017) Trends in beverage prices following the introduction of a tax on sugarsweetened beverages in Barbados. Prev Med, (Epublication ahead of print version).

29. Delga Y (2017) Chilean Government plans to ram through new tax on sugary foods. https://panampost.com/ysol-delgado/ 2017/01/13/chilean-government-plans-ram-new-tax-sugaryfoods/ (accessed October 2017).

30. Taillie LS, Rivera JA, Popkin BM et al. (2017) Do high vs. low purchasers respond differently to a nonessential energydense food tax? Two-year evaluation of Mexico's $8 \%$ nonessential food tax. Prev Med, (Epublication ahead of print version).

31. Hawkes C, Alderman H, Chaloupka F et al. (2017) Principles behind evaluations of national food and beverage taxes and other regulatory efforts. Obes Rev 18, 1374-1375. 